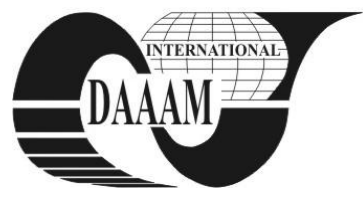

\title{
FUNDAMENTAL FACTS ABOUT MANUAL ASSEMBLY SYSTEMS
}

\section{BURANSKY, I[van]; VACLAV, S[tefan]; POKORNY, P[eter] \& BENOVIC, M[artin]}

Abstract: The paper deal with the assembly systems on which work peoples and product is in still stand during the assembly. This system prevails now.

There are six of sorts of systems differed with the time of assembly of one product, with the level of flexibility and humanization of the human work

Key words: assembly, mechanization, systems, humanization

\section{INTRODUCTION}

Till now we know six of the sorts of the stepped assembly system (fig. 1, fig 2).

Many people believe that the best solutions are the standard synchronous (a) and asynchronous (c) lines. There are many myths about special advantages of the asynchronous lines comparing with the synchronous lines, as for humanization of the work and hours output.
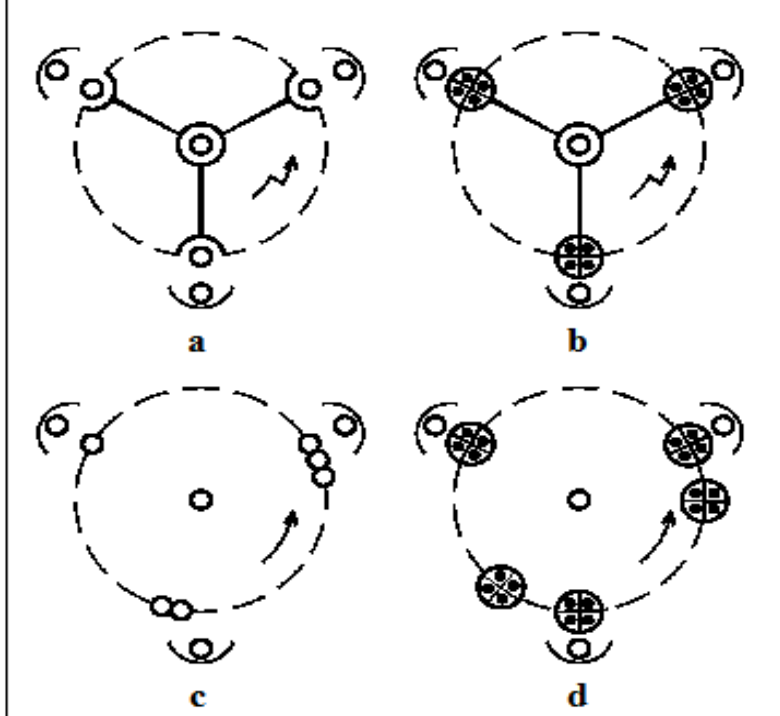

Fig. 1. Classification of the stepped assembly systems a - Synchronous line,

b - Synchronous batch line,

c - Asynchronous line,

d - Asynchronous batch line.

With that myth we will deal in the special paper. We will not deal with the systems in which the product is moving during the assembly. Those systems are not acceptable for man $(1,7)$.

Criterions of quality of system will be the time of the assembly of one product, production flexibility and the level of the humanization of the work $(3,5)$.

In this paper we will deal with hours output of over given systems in respect of the quality of assembled parts. We will analyze also the level of production flexibility and humanization of work.

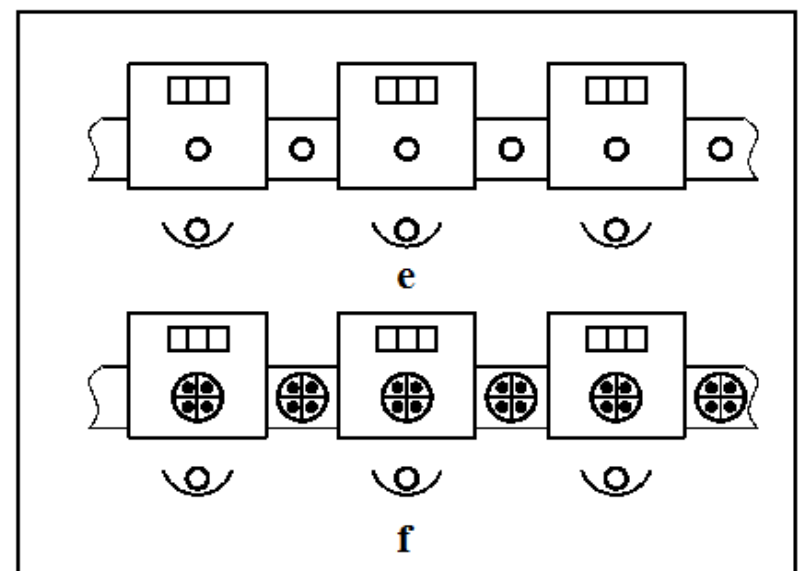

Fig. 2. Classification of the stepped assembly systems e - Parallel workplaces,

f - Parallel batch workplaces.

\section{CLASSIFICATION AND EVALUATION OF SYSTEMS}

Classification is on the fig. 1, evaluation from the aspect of the theoretical time of assembly of the one product $(\mathrm{T})$ is in the table 1(4).

The cycle times are calculated for over given systems under the same input data. It is surprising that the greater hours output have not the lines but the parallel workplaces.

The parallel workplaces have the great advantage in their production flexibility $(2,6)$.

The system is able to produce by arbitrary number of the disposable workers. Every workplace can assemble different product.

The great advantages have this system in the humanization of the work. Only on this systems have the workers full working freedom.

\section{IDEAL AND REAL HOURS OUTPUT}

In the table 1 was calculated ideal cycle times (T) supposing that the all input parts are good and values $\eta_{\mathrm{i}}$ in the equations (1) is $\eta_{i}=1$.

Efficiency of the system with real parts is.

$$
\eta_{\mathrm{i}}=\eta_{1} \times \eta_{2} \times \eta_{3} \times \ldots \times \eta_{\mathrm{i}} \mathrm{x} \ldots \mathrm{x} \eta_{\mathrm{n}}
$$

Where:

$\eta_{i}$ is efficiency of its part, $\eta_{\mathrm{s}}$ is efficiency of the all system, $\eta_{i}=0,9$ meant that $90 \%$ of the its parts are good $\eta_{\mathrm{s}}=0,8$ meant that when into the system enter 100 sets of parts of product from the system go out only 80 good product. 
We are not interested on the behaviour of separate stations but behaviour of the all system. If $\eta_{\mathrm{s}}$ is 1 the hours output will be:

$$
\begin{aligned}
& H=\frac{3600}{T} \\
& H=\frac{3600}{T} \bullet \eta_{s}
\end{aligned}
$$

We supposed that the system work without stopping and it produce good products from the good parts or bat product if same parts are bad. That situation is seldom.

The system is often stopped for repairing and maintenance. $\eta_{\mathrm{t}}$ is time efficiency of system. $\eta_{\mathrm{t}}=0,9$ it means that system work only in $90 \%$ of disposable time. The hours output will be then:

$$
H=\frac{3600}{T} \bullet \eta_{s} \bullet \eta_{t}
$$

Example:

The efficiency of system $\eta_{\mathrm{s}}$ (eq. 1) is for four parts product:

$$
\mathrm{H}_{\mathrm{s}}=0,98 \times 0,96 \times 0,97 \times 0,98=0,91
$$

Time efficiently is $\eta_{t}=0,85$. Theoretical cycle time (tab. 1) is $\mathrm{T}=5 \mathrm{~s}$. The hours output will be:

$$
H=\frac{3600}{5} \bullet 0,91 \bullet 0,85=556 \text { pieces } / \text { hour }
$$

In many cases the values $\eta_{t}$ and $\eta_{t}$ are not disposable. Often

\begin{tabular}{|c|c|c|c|}
\hline $\begin{array}{l}\mathrm{T} \\
\mathrm{y} \\
\mathrm{p}\end{array}$ & General formulas & \multicolumn{2}{|c|}{ Examples [s] } \\
\hline $\mathrm{a}$ & $\mathrm{T}=\mathrm{O}_{\max }+\mathrm{S}$ & $3+1=$ & $4 \mathrm{~s}$ \\
\hline b & $T=\frac{O_{\max .} n+S}{n}$ & $\frac{3.4+1}{4}$ & $3,25 \mathrm{~s}$ \\
\hline $\mathrm{c}$ & $\mathrm{T}=\mathrm{O}_{\max }+\mathrm{S}$ & $3+1$ & $4 \mathrm{~s}$ \\
\hline d & $T=\frac{O_{\max } \cdot n+S}{n}$ & $\frac{3.4+1}{4}$ & $3,25 \mathrm{~s}$ \\
\hline $\mathrm{e}$ & $T=\frac{\left(O_{1}+O_{2}+O_{3}\right) \cdot n+S}{q}$ & $\frac{3+2+1+1}{3}$ & $2,3 \mathrm{~s}$ \\
\hline $\mathrm{f}$ & $T=\frac{\left(O_{1}+O_{2}+O_{3}\right) \cdot n+S}{q}$ & & $2,08 \mathrm{~s}$ \\
\hline
\end{tabular}
are estimated according to similar realized systems.

The important influence on the hours output have the time of the step (S) time of reposition of the product to the second work station (tab.1).

Tab. 1. Comparison of the theoretical times of production of the one product $\mathrm{T}[\mathrm{s}]$ on the failure free system (theoretical tact)

$\mathrm{O}_{1}$ - time of the assembly of first part, $\mathrm{O}_{1}=3 \mathrm{~s}$,

$\mathrm{O}_{2}$ - time of the assembly of second part, $\mathrm{O}_{2}=2 \mathrm{~s}$,

$\mathrm{O}_{3}$ - time of the assembly of third part, $\mathrm{O}_{3}=1 \mathrm{~s}$,

$\mathrm{S}$ - time of step, $\mathrm{S}=1 \mathrm{~s}$,

$\mathrm{n}$ - number of parts in the one batch, $\mathrm{n}=4$,

$q-$ number of workplaces.

This time will be lower when density of carriers in the batch is higher and when instead of stepping of the one product are stepped the all members of the batch.

The time of the step will be lover if the dynamics of the movement is optimal. Synchronous line has this movement realized with good dynamic (cams mechanic).
The advantage of the bath carriers are that worker can to assembly the all batch by one grasping of the instrument. On the all described systems we supposed that on the every workplace is one worker. In the final car assembly is successfully introduced the workplaces with 2,3 or 4 workers (The group work). Modern lines have the maximal possible content of the work on the one station of the line. Taylor's atomization of the work is overcome.

\section{CONCLUSION} parts.

Peoples worked in the plants are now divided on the two

1. Peoples with the time freedom,

2. Peoples without line freedom.

The first group muss to fill his asks till the given limit but they can to change tempo of the work.

The second group muss $t$ work in the given (often very short tempo less than one minute) in the uncomforted body position (standing or stepping) without possibility of communication with colleagues and without possibility of personal pauses.

There are not peoples who are interested to work without time freedom today.

The solution of problem is not to shift the assembly plants into low developed countries.

The solution is to find the assembly systems with high productivity with high process and personal flexibility with rich content of operations with possibility to change the position of body (sitting, standing) with possibility to cooperate an to communicate with colleagues and with maximal possible time freedom.

This paper can help to find that solutions.

Full automation of assembly is problem technical but mainly economical.

\section{ACKNOWLEDGEMENTS}

I hearty thank to my teacher ass. prof. Valentovič to his valuable recommendation to this work.

This article was written for grant project VEGA 1/0250/11

We are indebted for support.

\section{REFERENCES}

Boothroyd,G.; Redford, A. H.(1968). Mechanized Assembly, Mc. Graw-Hill. London 1968

Mareš, A., Senderská, K., (2005). Modernization of manual assembly workstation. In: 5th. International conference Research and development in mechanical industry RADMI 2005. Vrnjačka Banja (Serbia and Montenegro) - High Technical Mechanical School of Trstenik, p. 188 - 191. ISBN 86-83803-20-1

Madarász, Ladislav - Kováč, Jozef - Senderská, Katarína (2008): Selection of assembly system type, 2008.In: SAMI 2008. - Budapest : Budapest Tech, p. 45-47. - ISBN 9781424421060

Fabian, Michal - Spišák, Emil - Šeminský, Jaroslav Senderská, Katarína - Mareš, Albert - Ižol, Peter (2010): CAM parameters settings and NC milled surface quality, 2010.In: Annals of DAAAM for 2010 \& Proceedings of the 21th international DAAAM symposium. - Vienna : DAAAM International, 2010 Vol. 21, no. 1, p. 0391-0392. ISBN 978-3-901509-73-5 - ISSN 1726-9679

Valentovič, E., Janáč, A. \&Václav, Š. (2004). Humanization of Assembly. In MATAR PRAHA 2004 - Machine tools, automation and robotics in mechanical engineering. Praha: ČVUT, p. 328-332. ISBN $80903421-4-0$

Warnecke, H.J.; Lohr, H.G. \& Keiner, W. (1975). Montagetechnik-Schwerpunkt der Rationalisierung. Otto Kraus Verlag, Mainz 